\title{
The Validity and Reliability of the Persian Version of the Family Health Climate Scale (FHC-Scale) in Female Students and Their Mothers in Iran 2019
}

\author{
Jeyran Ostovarfar $\left(\mathbb{D},{ }^{1}\right.$ Mohammad Hossein Kaveh $\mathbb{D},{ }^{2}$ Leila Ghahramani $\left(\mathbb{D},{ }^{2}\right.$ \\ Masoud Karimi $\odot,{ }^{2}$ Abdolrahim Asadollahi $\odot{ }^{2}$ and Razie Zare $\oplus^{3}$ \\ ${ }^{1}$ Department of Health Promotion, Shiraz University of Medical Sciences School of Health and Nutrition, Shiraz 71557, Iran \\ ${ }^{2}$ Department of Health Promotion, School of Health, Shiraz University of Medical Sciences, Shiraz 71557, Iran \\ ${ }^{3}$ Industrial \& Organizational Psychology Department, Faculty Education \& Psychology, Shahid Chamran University, \\ Ahvaz 61336, Iran
}

Correspondence should be addressed to Mohammad Hossein Kaveh; mhkaveh255@gmail.com

Received 18 September 2020; Revised 15 December 2020; Accepted 27 January 2021; Published 8 February 2021

Academic Editor: Solomon Yimer

Copyright (c) 2021 Jeyran Ostovarfar et al. This is an open access article distributed under the Creative Commons Attribution License, which permits unrestricted use, distribution, and reproduction in any medium, provided the original work is properly cited.

\begin{abstract}
Objectives. This study examined the validity and reliability of the Family Health Climate Scale (FHC-Scale) among Iranian families. Second, can it be attributed to other family members by measuring the health climate in one person? Method. In total, 261 female students and 196 mothers completed the FHC-Scale. The study instrument was a Persian version of the FHC-Scale prepared through a translation and back-translation process. Results. The results showed that the Persian version of the FHC-Scale is acceptable. Cronbach's alpha coefficient for FHC-PA in female students and their mothers, respectively, was 0.88 and 0.86 for the whole scale. Cronbach's alpha coefficient for FHC-NU in female students and their mothers, respectively, was 0.83 and 0.92 for the whole scale. The CVI values for all the items were equal to or above 0.8 , and the CVR value for the total scale was 0.90 . Conclusion. The Persian version of the FHC-Scale is therefore an effective tool for evaluating the different dimensions of family health climate in the Iranian population.
\end{abstract}

\section{Introduction}

Health behaviors learned during childhood easily remain in people's lifestyles and will have more permanent effects compared to behaviors obtained in adulthood [1]. A healthy lifestyle is determined by many factors, including individual, social, physical, and environmental factors and their interaction. People's health behavior patterns are not developed and maintained in a vacuum. Health behaviors are embedded in social contexts and are influenced by social relationships, which are among the most important social contexts of the family $[2,3]$.

1.1. Health Behaviors in the Family Environment. Many studies have focused on the effects of the family environment on the parent-child relationship and the effect of parental behav- iors on children's behaviors. Previous research has shown the important role of parents in creating a healthy lifestyle in their children [4, 5]. Parents are the gatekeepers who determine the healthy nutrition and physical activity of their children. For example, by determining what food is available at home, they shape their children's eating habits. Access to sports equipment is also provided by parents. Other influential factors include parenting styles, such as role modeling, supervision, support, and encouragement [6-9], and more general concepts such as parenting styles $[10,11]$. In fact, parents' role modeling of healthy behaviors can increase healthy behaviors in their children [12]. In general, positive parenting is positively correlated to children's healthy eating behaviors and physical activity levels $[13,14]$. Family members, on the other hand, interact in a shared family environment. Individuals and the interaction between them affect 
the family environment, which in turn affects individuals and their interactions. Therefore, the "family level" is beyond individuals and their shared environment, and consequently, the family can be considered a system [15].

1.2. Family Health Climate in the Family System. Evidence has shown a link between diet and physical activity [16, 17]. Family refers to a group of individuals, and all members of this group have specific motivations, influences, and behaviors. Individuals within a family interact with each other. These interactions occur over a long period of time and at a high frequency, forming the "family system" that is one of the fundamental components of the family environment. Approaching family as a system, the fundamental questions are how the family environment affects an individual's health behaviors and how this effect can be described. It has been stated that a particular aspect of family members' interactions shapes individuals' physical activity and eating behaviors, which is called the "climate." In description of the environmental dimensions of the family that lead to the creation of individual health behaviors, the term climate has been judged as a special feature $[18,19]$. The term "family health climate" was introduced by Niermann et al. [20].

1.3. Health-Related Behaviors and Family Health Climate. Family health climate has been defined as the shared perceptions and cognitions concerning health and health behaviors. It reflects the individual experience of daily family life, evaluation of health-related topics, and expectations with respect to typical values, behavior routines, and interaction patterns within the family [20].

Parents and children are parts of the family and influence each other's behaviors, and this indicates reciprocal influence. These family interactions and perspectives are a part of the family health climate $[18,19]$. Because a specific understanding of the family climate predicts particular behaviors [21], and behaviors such as eating and physical activity are completely different in spite of being related to health [22]; this tool includes climate perceptions that refer to these behaviors [20].

According to a scale developed by Niermann et al., the family health climate influences the health behaviors of family members. Family health climate can be measured using the Family Health Climate for Physical Activity (FHC-PA) Scale and the Family Health Climate for Nutrition (FHCNU) Scale. By measuring the family health climate of a family member, the results can be attributed to the whole family [20]. To prove this claim, the present study was conducted on two family members.

The Family Health Climate Scale focuses on the typical aspects of the family environment (e.g., communication, time together, encouragement, and connectedness) and represents emotional, cognitive, and instrumental aspects of the family environment. According to the specificity of different health behaviors, this instrument includes two separate scales: FHC-PA with 14 questions and FHC-NU with 17 questions [20].
1.4. Objects. In response to the lack of investigations of the validity and reliability of the Family Health Climate Scale after its development and validation by Niermann et al., the present study is aimed at examining the validity and reliability of this questionnaire among Iranian families. It is also aimed at determining whether the measurement of health climate in one person can be attributed to other family members.

\section{Materials and Methods}

This cross-sectional study was conducted to evaluate the validity and reliability of the Family Health Climate Scale and to assess its generalizability from an individual to other family members among Iranian female students and their mothers in Shiraz 2019.

2.1. Participants. The study participants were fifth-grade female students who studied in Shiraz schools as the first target group. Since various studies have indicated that mothers' healthy behaviors have a greater impact on children compared to the paternal model [23], emotional dependence is stronger in the mother-daughter relationship and the nature of the relationship plays an important role in girls' social and psychological well-being [24], and the mother-daughter relationship is unique and significant because of the solidarity and support provided by women [25, 26], mothers were selected as the second group.

The participants were selected from the four educational districts in Shiraz using cluster sampling. At first, two out of the four districts were randomly selected (districts 2 and 4). In each of the selected districts, four public schools were randomly selected. In each school, two classes were randomly selected, and eventually, 261 female students were selected. After the students were explained about the study objectives, they were given two questionnaires: one for themselves and one for their mothers. The students were asked to give the questionnaires to their mothers. The students and their mothers were required to complete the questionnaires and return them to the researcher within one week. Because of the researcher's relationship with the students, all students completed the questionnaires, and 196 mothers completed the questionnaires that are about $75 \%$.

2.2. Family Health Climate Scale. Family Health Climate Scale includes two separate scales: FHC-PA and FHC-NU. FHC-PA contains 14 questions with three subscales (value, for example, "it is normal in our family to be physically active in our leisure time"; cohesion, for example, "...we have fun doing physical activities together (e.g., bike tours and hikes)"; and information, for example, "we collect information (e.g., on the internet) on physical activity and exercise") [20]. FHC-NU consists of 17 questions with four subscales (value, for example, "a healthy diet plays an important role in our lives"; communication, for example, "we talk about which foods are healthy"; cohesion, for example, "we appreciate spending time together during meals"; and consensus, for example, "we rarely argue about food- or diet-related matters"). All questions were begun with "In our family...," 
and answers were given on a four-point rating scale $(0=$ "definitely false," 1 = "rather false," 2 = "rather true," and 3 = "definitely true") [20].

In a study by Niermann et al., mothers, fathers, and adolescents completed a questionnaire separately. The internal correlation was $\alpha \mathrm{FHC}-\mathrm{PA}=0.92$ and $\alpha \mathrm{FHC}-\mathrm{NU}=0.86$ for the mothers, $\alpha$ FHC-PA $=0.90$ and $\alpha \mathrm{FHC}-\mathrm{NU}=0.86$ for the fathers, and $\alpha \mathrm{FHC}-\mathrm{PA}=0.90$ and $\alpha \mathrm{FHC}-\mathrm{NU}=0.85$ for the adolescents [20].

\subsection{Persian Translation of the Family Health Climate Scale.} The Family Health Climate Scale was translated according to the four sequential stages of translation and backtranslation as recommended by Chen et al. [27]. The translation instructions emphasized conceptual rather than literal accuracy as well as the need to use an acceptable linguistic approach for the majority of Persian-speaking participants. This meant an avoidance of technical terms and jargons.

The bilingual expert panel consisted of the original translator, experts in public health, and experts in translation and development of questionnaires. This panel was required to sort out discrepancies and to reach a consensus regarding the translated version of the scale.

The initial forward translation into Persian was backtranslated to English by a single independent translator for whom English was the mother tongue and who had no knowledge related to the questionnaire. The back-translated English version was then cross-matched with the original English version.

A pretesting phase was carried out on ten participants from the same sampling group who were not involved in the main study. The instrument was administered to the participants after a short explanation of the content. Face-to-face interview sessions were conducted by the primary investigator. The answers obtained from these sessions were matched with the actual responses given by the respondents. The respondents were also interviewed regarding the questionnaire content and ease of understanding.

\section{Results}

3.1. Content Validity. The face and content validity of the translated version was assessed by a group of experts consisting of 15 academic staff of Shiraz University of Medical Sciences who had work experience in the field of Epidemiology and Health Education and Promotion. Clarity of the wording, placement of the items, and scoring were checked by the experts at this stage, and their feedbacks were followed to make corrections. Content Validity Ratio (CVR) and Content Validity Index (CVI) were calculated based on the experts' opinions in terms of relevance, clarity, and simplicity of the items in the translated scale. The CVI values were equal to or above 0.8 for all items, and the CVR value was 0.90 for the total scale. In the end, to confirm face validity, the scale was given to 10 female students and their mothers for feedback on the simplicity of the scale and understandability of items so that possible ambiguities could be further refined.
3.2. Construct Validity. In the first step, the construct validity of the Family Health Climate Scale was determined to extract the number of hidden factors using exploratory factor analysis. For both FHC-PA and FHC-NU scales, assumptions for exploratory factor analysis were confirmed (FHC-PA: Kaiser-Meyer-Olkin $=0.84$, Bartlett's test of sphericity $=$ 2522.66, df = 91, $p<0.001$; FHC-NU: Kaiser-Meyer-Olkin $=0.82$, Bartlett's test of sphericity $=1449.02, \mathrm{df}=136, p<$ $0.001)$. The results of these indicators showed an optimal correlation between the variables that made factor analysis possible. Factors in the test were extracted by principal component analysis and varimax rotation for both FHC-PA and FHC-NU scales. In this model, three factors were extracted for FHC-PA according to eigenvalues higher than one. The eigenvalues of the three hidden factors were 5.76, 1.84, and 1.62 after rotation. The three extracted factors explained $65.91 \%$ of the total variance of the construction of the FHC-PA in female students. Considering FHC-NU, four factors were extracted according to eigenvalues higher than one. The eigenvalues of the four hidden factors were 4.74, 2.54, 1.51 , and 1.12 after rotation. The four extracted factors explained $58.42 \%$ of the total variance of the construction of FHC-NU in female students. The exploratory factors extracted from the Family Health Climate Scale are presented in Table 1.

In the second step, to assess the fitness of the final model of the three-factor structure of FHC-PA and the four-factor structure of FHC-NU, confirmatory factor analysis was performed on the mothers. To test the assumed factor structures (confirmation of the extracted factors), confirmatory factor analysis was performed using AMOS software. To this end, a model based on the previous information about data structure was developed, and the data for the model were analyzed. Findings from the implementation of confirmatory factor analysis through eight evaluation criteria, including the value of the chi-square index, normed $\chi^{2}$ measure index (the chi-square ratio of the degree of freedom), goodness of fit index (GFI), adjusted goodness of fit index (AGFI), normed fit index (NFI), comparative fit index (CFI), incremental fit index (IFI), Tucker-Lewis index (TLI), and root mean square error of approximation (RMSEA), are shown in Table 2. The factor structure of the FHC-PA scale in the present study is presented in Figure 1. Accordingly, all items had moderate to high factor loads $(p<0.001)$. Additionally, the indicators of the confirmatory factor analysis model of FHC-PA demonstrated that the measures of the indicators were close to the fitness criteria and that the confirmatory factor analysis model had an acceptable fit. The fitness indicators of the factor analysis model of FHC-PA are presented in Table 2. As the table depicts, the fitness indices of the confirmatory factor analysis model of FHC-PA in the present study were acceptable. The factor structure of FHC-NU is shown in Figure 2. Accordingly, all items had moderate to high factor loads $(p<0.001)$. Moreover, the indicators of the confirmatory factor analysis model of FHC-NU revealed that the measures of the indicators were close to the fitness criteria and that the confirmatory factor analysis model had an acceptable fit. The fitness indicators of the factor analysis 
TABLe 1: Exploratory factors extracted from the Family Health Climate Scale (student sample).

\begin{tabular}{|c|c|c|c|c|c|}
\hline Scales & Domain & Original item code & Factor loadings & Item share & Eigenvalues \\
\hline \multirow{13}{*}{ FHC-PA } & \multirow{4}{*}{ Information } & Q3 & 0.846 & 0.982 & \multirow{4}{*}{5.57} \\
\hline & & Q4 & 0.863 & 0.982 & \\
\hline & & Q1 & 0.786 & 0.503 & \\
\hline & & Q2 & 0.734 & 0.506 & \\
\hline & \multirow{5}{*}{ Cohesion } & Q3 & 0.841 & 0.630 & \multirow{5}{*}{1.84} \\
\hline & & Q1 & 0.840 & 0.578 & \\
\hline & & Q2 & 0.769 & 0.508 & \\
\hline & & Q5 & 0.640 & 0.511 & \\
\hline & & Q4 & 0.552 & 0.411 & \\
\hline & \multirow{5}{*}{ Value } & Q2 & 0.777 & 0.431 & \multirow{5}{*}{1.62} \\
\hline & & Q1 & 0.772 & 0.486 & \\
\hline & & Q5 & 0.742 & 0.448 & \\
\hline & & Q3 & 0.701 & 0.546 & \\
\hline \multirow{18}{*}{ FHC-NU } & & Q4 & 0.657 & 0.418 & \\
\hline & \multirow{5}{*}{ Communication } & Q2 & 0.797 & 0.436 & \multirow{5}{*}{4.74} \\
\hline & & Q3 & 0.740 & 0.433 & \\
\hline & & Q4 & 0.703 & 0.436 & \\
\hline & & Q1 & 0.653 & 0.653 & \\
\hline & & Q5 & 0.580 & 0.450 & \\
\hline & \multirow{5}{*}{ Value } & Q1 & 0.849 & 0.551 & \multirow{4}{*}{2.54} \\
\hline & & Q4 & 0.817 & 0.516 & \\
\hline & & Q2 & 0.810 & 0.451 & \\
\hline & & Q3 & 0.786 & 0.473 & \\
\hline & & Q4 & 0.819 & 0.361 & \multirow{5}{*}{1.51} \\
\hline & \multirow{4}{*}{ Cohesion } & Q5 & 0.686 & 0.355 & \\
\hline & & Q2 & 0.586 & 0.417 & \\
\hline & & Q1 & 0.564 & 0.331 & \\
\hline & & Q3 & 0.554 & 0.275 & \\
\hline & \multirow{3}{*}{ Consensus } & Q3 & 0.786 & 0.450 & \multirow{3}{*}{1.12} \\
\hline & & Q2 & 0.766 & 0.430 & \\
\hline & & Q1 & 0.618 & 0.205 & \\
\hline
\end{tabular}

TABLE 2: The indicators of fitness of the factor analysis of the FHC-PA scale among the mothers.

\begin{tabular}{lcccccccccc}
\hline Structure fitness indicators & $\chi^{2}$ & $\mathrm{df}$ & $\chi^{2} / \mathrm{df}$ & GFI & AGFI & IFI & TLI & CFI & NFI & RMSEA \\
\hline Three-dimensional structure & 222.703 & 73 & 3.051 & 0.88 & 0.83 & 0.94 & 0.92 & 0.94 & 0.91 & 0.09
\end{tabular}

GFI: goodness of fit index; AGFI: adjusted goodness of fit index; IFI: incremental fit index; TLI: Tucker-Lewis fit index; CFI: comparative fit index; NFI: normed fit index; RMSEA: root mean square error of approximation.

model of FHC-NU are presented in Table 3. As the table depicts, the fitness indices of the confirmatory factor analysis model of FHC-NU in the present study were acceptable.

3.2.1. Reliability. To evaluate the reliability of both FHC-PA and FHC-NU scales, Cronbach's alpha and split-half methods were used; the results of which are reported in Table 4. Accordingly, both FHC-PA and FHC-NU scales had good reliability.
3.3. Perception of Mothers and Female Students of the Family Health Climate. Paired $t$-test was used to analyze different perceptions of family health climate among students and their mothers. The results of paired sample $t$-test are presented in Table 5 . The results revealed a significant difference between the students' and their mothers' perceptions of FHC-NU.

3.3.1. Components. The results of paired $t$-test for FHC-NU components showed that the communication component 


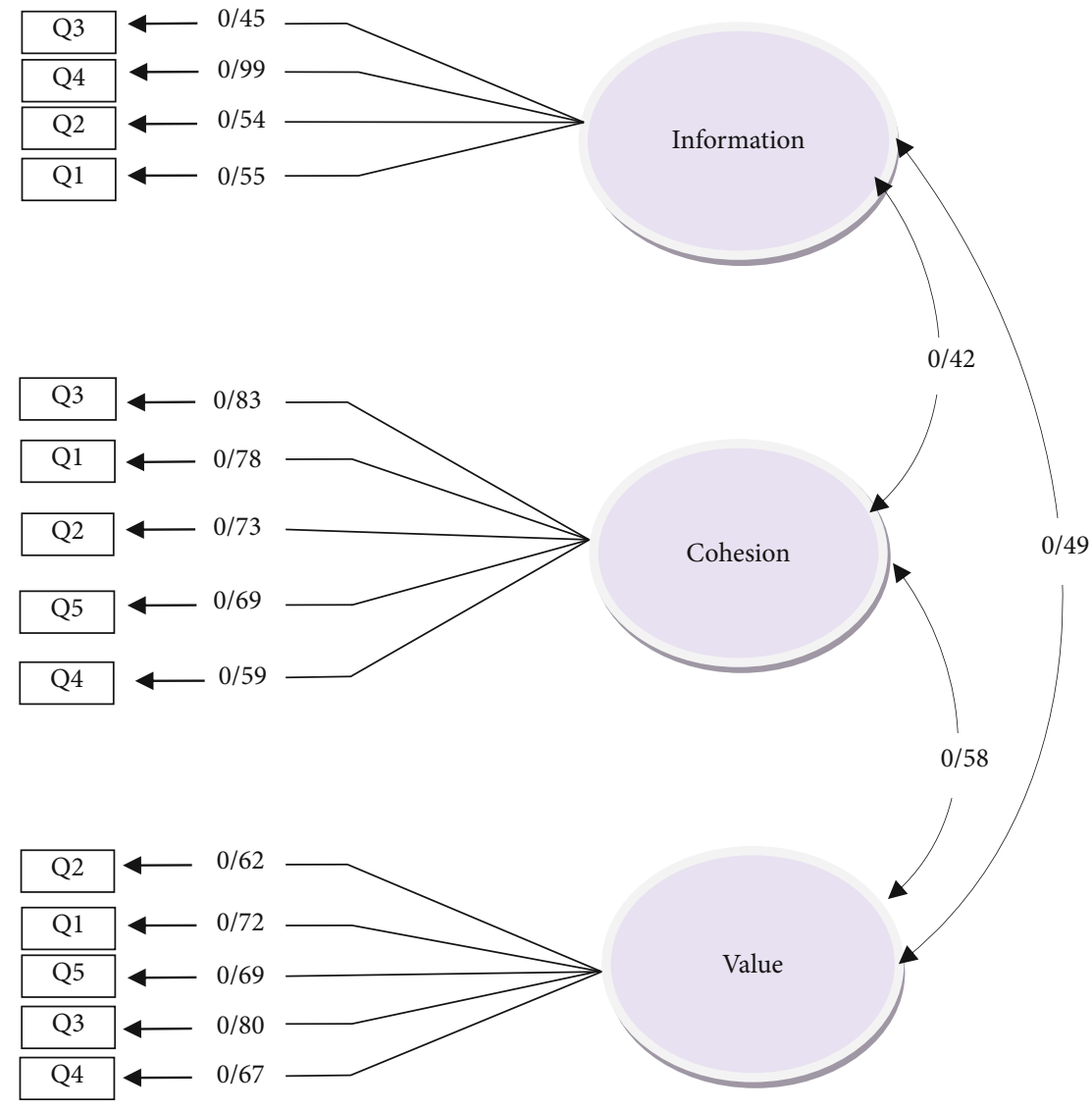

FIGURE 1: Factor structure of FHC-PA (mothers' sample).

was perceived differently by the students and their parents $(p<0.01)$. Accordingly, the mean score of communication perceived by the students was significantly higher compared to that by the mothers.

Based on Table 6 , the results of paired sample $t$-test indicated a significant difference between the students and their parents regarding their perceptions of FHC-PA.

3.3.2. Components. The results of paired $t$-test for FHC-PA components showed that the value, cohesion, and to some extent information components were perceived differently by the students and their parents $(p<0.05)$. Accordingly, the mean scores of value and cohesion perceived by the students were significantly higher compared to those by the mothers.

\section{Discussion}

This was the first study on the validity and reliability of the Family Health Climate Scale after its development and validation by Niermann et al. This study confirmed that the Family Health Climate Scale had appropriate construct validity, content validity, discriminant validity, and internal consistency, which indicated that the Persian version of the scale followed a logical and appropriate trend.
Reliability means repeatability, and it is assessed through various methods [28]. In the present study, reliability was evaluated using internal consistency and split-half methods. Cronbach's alpha coefficient for FHC-PA was 0.88 in the female students and 0.86 in the mothers. In the research carried out by Niermann et al., the internal consistency coefficients ranged from 0.81 to 0.9 for FHC-PA [20]. In the current study, Cronbach's alpha coefficient for FHC-NU was 0.84 among the female students and 0.92 among the mothers. In the study by Niermann et al., the internal consistency coefficients ranged from 0.74 to 0.90 for FHC-NU [20].

The reliability coefficient obtained using the split-half method for FHC-PA was 0.73 among the female students and 0.70 in their mothers. Considering FHC-NU, the reliability coefficient was 0.71 for the female students and 0.84 for their mothers. According to McKelvie [29], these values indicated the acceptable reliability of the Persian version of the scale.

The fitness indicators of the confirmatory factor analysis model presented in Tables 3 and 4 showed that both FHC-PA and FHC-NU components of the Persian version of the Family Health Climate Scale had desirable conditions and were consistent with the fitness indicators of the confirmatory factor analysis model of the original version created by Niermann et al. The validity of the scale was also acceptable according to the commonly recommended fit indices. In this 


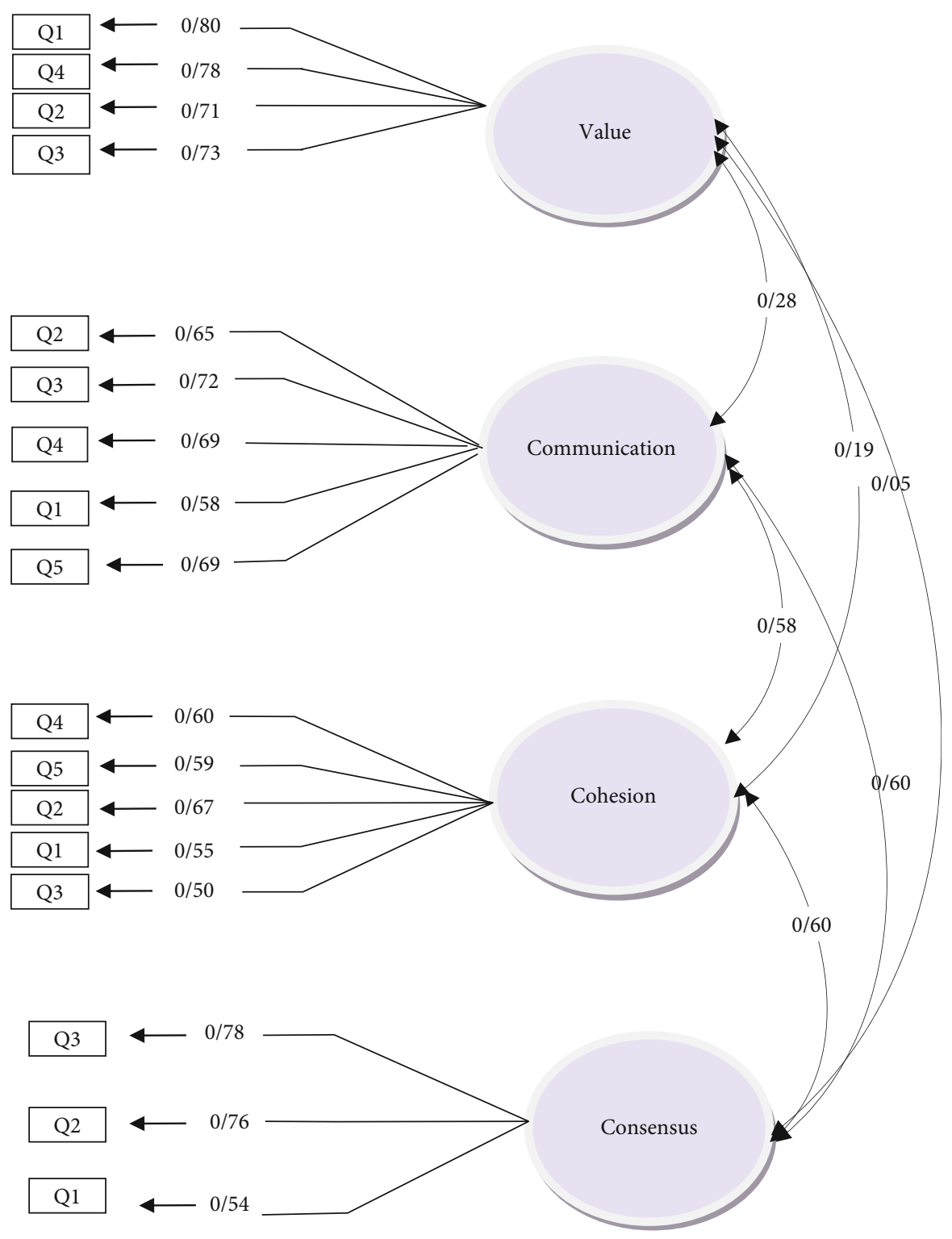

FIGURE 2: Factor structure of FHC-NU (mothers' sample).

TABLE 3: The indicators of fitness of the factor analysis of the FHC-NU scale in the mothers.

\begin{tabular}{|c|c|c|c|c|c|c|c|c|c|c|}
\hline Structure fitness indicators & $\chi^{2}$ & $\mathrm{df}$ & $\chi^{2} / \mathrm{df}$ & GFI & AGFI & IFI & TLI & CFI & NFI & RMSEA \\
\hline Four-dimensional structure & 205.802 & 113 & 1.821 & 0.91 & 0.93 & 0.91 & 0.92 & 0.93 & 0.86 & 0.05 \\
\hline
\end{tabular}

GFI: goodness of fit index; AGFI: adjusted goodness of fit index; IFI: incremental fit index; TLI: Tucker-Lewis fit index; CFI: comparative fit index; NFI: normed fit index; RMSEA: root mean square error of approximation.

study, $\chi^{2} / \mathrm{df}, \mathrm{CFI}$, standardized root mean square residual (SRMR), and RMSEA were used to assess the goodness of fit. A good fit is indicated by $0 \leq \chi^{2} / \mathrm{df} \leq 2,0.97 \leq \mathrm{CFI} \leq 1,0$ $\leq \mathrm{SRMR} \leq 0.05$, and RMSEA $\leq 0.05$, while values $2<\chi^{2} / \mathrm{df}$ $\leq 3, \quad 0.95 \leq \mathrm{CF}<0.97, \quad 0.05<\mathrm{SRMR} \leq 0.10$, and $0.05<$ RMSEA $\leq 0.08$ indicate an acceptable fit [30]. The concepts of nutrition and physical activity included in the Family Health Climate Scale are international concepts that are compatible with different cultures and languages and seem to be applicable all over the world; therefore, the consistency of the results of the present study with the results of the study of Niermann et al. is reasonable.

According to the results presented in Table 5, the mean score of FHC-NU was significantly higher in female students than in their mothers. The mean score of the communication subscale in FHC-NU was also significantly higher among the female students compared to their mothers. Mothers generally use role modeling to communicate health behaviors to their children to control their eating behaviors and constantly remind their children about healthy eating [31, 32]. 
TABle 4: The reliability coefficients of the Family Health Climate Scale.

\begin{tabular}{|c|c|c|c|c|c|c|c|c|c|}
\hline \multirow{2}{*}{ Scales } & \multirow{2}{*}{ Domains } & \multicolumn{4}{|c|}{ Mothers } & \multicolumn{4}{|c|}{ Female students } \\
\hline & & \multicolumn{2}{|c|}{ Cronbach's $\alpha$} & \multicolumn{2}{|c|}{ Split-half } & \multicolumn{2}{|c|}{ Cronbach's $\alpha$} & \multicolumn{2}{|c|}{ Split-half } \\
\hline \multirow{3}{*}{ FHC-PA } & Information & 0.84 & \multirow{3}{*}{0.86} & 0.70 & \multirow{3}{*}{0.70} & 0.87 & \multirow{3}{*}{0.88} & 0.75 & \multirow{3}{*}{0.73} \\
\hline & Cohesion & 0.77 & & 0.67 & & 0.84 & & 0.71 & \\
\hline & Value & 0.84 & & 0.78 & & 0.82 & & 0.75 & \\
\hline \multirow{4}{*}{ FHC-NU } & Cohesion & 0.96 & \multirow{4}{*}{0.92} & 0.87 & \multirow{4}{*}{0.84} & 0.79 & & 0.72 & \multirow{4}{*}{0.71} \\
\hline & Value & 0.92 & & 0.88 & & 0.84 & & 0.82 & \\
\hline & Communication & 0.97 & & 0.93 & & 0.71 & 0.83 & 0.69 & \\
\hline & Consensus & 0.96 & & 0.84 & & 0.68 & & 0.70 & \\
\hline
\end{tabular}

TABLE 5: The results of paired sample $t$-test for comparison of FHC-NU as perceived by the female students and as rated by the mothers.

\begin{tabular}{|c|c|c|c|c|c|c|c|c|}
\hline Variable & Mean & $N$ & Std. deviation & Std. error of mean & Mean difference & $T$ & $\mathrm{df}$ & Sig. \\
\hline FHC-NU (female students) & 28.48 & 196 & 9.837 & 0.702 & \multirow{2}{*}{2.045} & \multirow{2}{*}{2.235} & \multirow{2}{*}{195} & \multirow{2}{*}{0.027} \\
\hline FHC-NU (mothers) & 26.43 & 196 & 8.999 & 0.642 & & & & \\
\hline FHC-NU value (female students) & 6.55 & 196 & 3.483 & 0.248 & \multirow{2}{*}{-2.295} & \multirow{2}{*}{-0.770} & \multirow{2}{*}{195} & \multirow{2}{*}{0.442} \\
\hline FHC-NU value (mothers) & 6.78 & 196 & 2.467 & 0.176 & & & & \\
\hline FHC-NU communication (female students) & 10.83 & 196 & 3.837 & 0.274 & \multirow{2}{*}{1.984} & \multirow{2}{*}{5.434} & \multirow{2}{*}{195} & \multirow{2}{*}{0.000} \\
\hline FHC-NU communication (mothers) & 8.84 & 196 & 3.715 & 0.265 & & & & \\
\hline FHC-NU cohesion (female students) & 7.69 & 196 & 4.356 & 0.311 & \multirow{2}{*}{0.729} & \multirow{2}{*}{1.887} & \multirow{2}{*}{195} & \multirow{2}{*}{0.061} \\
\hline FHC-NU cohesion (mothers) & 6.96 & 196 & 3.858 & 0.275 & & & & \\
\hline FHC-NU-consensus (female students) & 3.40 & 196 & 2.936 & 0.209 & \multirow{2}{*}{-0.438} & \multirow{2}{*}{-1.576} & \multirow{2}{*}{195} & \multirow{2}{*}{0.117} \\
\hline FHC-NU consensus (mothers) & 3.84 & 196 & 2.460 & 0.175 & & & & \\
\hline
\end{tabular}

TABLE 6: The results of paired sample $t$-test for comparison of FHC-PA as perceived by the student and as rated by the mothers.

\begin{tabular}{|c|c|c|c|c|c|c|c|c|}
\hline Variable & Mean & $N$ & Std. deviation & Std. error of mean & Mean difference & $T$ & $\mathrm{df}$ & Sig. \\
\hline FHC-PA (female student) & 23.23 & 196 & 11.274 & 0.805 & \multirow{2}{*}{3.653} & \multirow{2}{*}{3.564} & \multirow{2}{*}{195} & \multirow{2}{*}{0.000} \\
\hline FHC-PA (mothers) & 19.58 & 196 & 8.895 & 0.635 & & & & \\
\hline FHC-PA value (female students) & 8.88 & 196 & 4.904 & 0.350 & \multirow{2}{*}{1.469} & \multirow{2}{*}{3.321} & \multirow{2}{*}{195} & \multirow{2}{*}{0.001} \\
\hline FHC-PA value (mothers) & 7.41 & 196 & 4.083 & 0.291 & & & & \\
\hline FHC-PA information (female student) & 5.35 & 196 & 4.480 & 0.320 & \multirow{2}{*}{0.760} & \multirow{2}{*}{1.849} & \multirow{2}{*}{195} & \multirow{2}{*}{0.066} \\
\hline FHC-PA information (mothers) & 4.59 & 196 & 3.426 & 0.244 & & & & \\
\hline FHC-PA cohesion (female student) & 9.00 & 196 & 4.989 & 0.356 & \multirow{2}{*}{1.423} & \multirow{2}{*}{3.073} & \multirow{2}{*}{195} & \multirow{2}{*}{0.002} \\
\hline FHC-PA cohesion (mothers) & 7.57 & 196 & 3.874 & 0.276 & & & & \\
\hline
\end{tabular}

As a result, children feel that talking about and supporting healthy eating is one of the family's priorities. Therefore, they understood the family health climate more than their mothers did.

In the current study, the mean scores of almost all subscales and the total mean score of the FHC-PA scale were higher among the female students in comparison to their mothers. This can be justified by the fact that the Family Health Climate Scale measures the family level, is scored by individuals, and is associated with individuals' understandings of the motivational and behavioral aspects of other family members [20] and that parents, especially mothers, use motivational messages and try to provide opportunities to engage their children in physical activities [33].

\section{Limitations}

Family health climate was measured only among females, because females care more about their health compared to males $[34,35]$. Thus, a more comprehensive study in which a statistical population of males is also present is recommended to be conducted on the issue. The other limitation of this research was the inability to have access to the target group to retest the Family Health Climate Scale due to the prevalence of the Coronavirus Disease (COVID-19).

\section{Conclusion}

The family health climate describes a family level, which is suspected to affect the health behaviors of the family 
members [20]. The Family Health Climate Scale is a valid and reliable instrument to measure the climate about healthy eating and physical activity in the family context.

Even in the same family, people seem to have different perceptions of the family health climate, which depends on the type of behaviors and motivations that other family members give to the person about healthy behaviors. This hypothesis can be tested by measuring the family health climate in other family members. In the present study, the high scores of the female students in both FHC-NU and FHC-PA scales compared to their mothers indicated that the mothers, as role models, tried to create a positive health climate for their children so as to encourage them towards healthy eating and physical activity.

Overall, the results of the present study showed that the Family Health Climate Scale could be used effectively in cross-cultural comparative studies among Persian-speaking communities.

\section{Data Availability}

The data used to support the findings of this study are available from the corresponding author upon request.

\section{Conflicts of Interest}

The authors declare that they have no conflicts of interest.

\section{Acknowledgments}

This article was extracted from the Ph.D. thesis in Health Education and Health Promotion. It was financially supported by the Vice-Chancellor for Research, Shiraz University of Medical Sciences in Shiraz, Iran (grant no. 98-0104019514). We are grateful to the schools, mothers, and students who have agreed to take part in the programme. The authors would like to thank Ms. A. Keivanshekouh at the Research Improvement Center of Shiraz University of Medical Sciences for improving the use of English in the manuscript.

\section{References}

[1] Y. S. Eo and J. S. Kim, "Family socioeconomic status, parental attention, and health behaviors in middle childhood: a crosssectional study," Nursing \& Health Sciences, vol. 22, no. 2, pp. 220-225, 2020.

[2] D. Umberson, R. Crosnoe, and C. Reczek, "Social relationships and health behavior across the life course," Annual Review of Sociology, vol. 36, no. 1, pp. 139-157, 2010.

[3] C. Y. Niermann, S. Spengler, and J. S. Gubbels, "Physical activity, screen time, and dietary intake in families: a clusteranalysis with mother-father-child triads," Frontiers in Public Health, vol. 6, p. 276, 2018.

[4] J. S. Gubbels, Environmental Influences on Dietary Intake of Children and Adolescents, Multidisciplinary Digital Publishing Institute, 2020.

[5] C. Y. Niermann, S. P. Kremers, B. Renner, and A. Woll, "Family health climate and adolescents' physical activity and healthy eating: a cross-sectional study with mother-father- adolescent triads," PLoS One, vol. 10, no. 11, article e0143599, 2015.

[6] C. B. Lam and S. M. McHale, "Developmental patterns and parental correlates of youth leisure-time physical activity," Journal of Family Psychology, vol. 29, no. 1, pp. 100-107, 2015.

[7] L. Johnson, C. H. M. van Jaarsveld, and J. Wardle, "Individual and family environment correlates differ for consumption of core and non-core foods in children," British Journal of Nutrition, vol. 105, no. 6, pp. 950-959, 2011.

[8] J. K. Larsen, R. C. Hermans, E. F. Sleddens, R. C. Engels, J. O. Fisher, and S. P. Kremers, "How parental dietary behavior and food parenting practices affect children's dietary behavior. Interacting sources of influence?," Appetite, vol. 89, pp. 246257, 2015.

[9] S. Gerards and S. Kremers, "The role of food parenting skills and the home food environment in children's weight gain and obesity," Current Obesity Reports, vol. 4, no. 1, pp. 3036, 2015.

[10] R. L. Vollmer and A. R. Mobley, "Parenting styles, feeding styles, and their influence on child obesogenic behaviors and body weight. A review," Appetite, vol. 71, pp. 232-241, 2013.

[11] N. Pearson, A. J. Atkin, S. J. Biddle, T. Gorely, and C. Edwardson, "Parenting styles, family structure and adolescent dietary behaviour," Public Health Nutrition, vol. 13, no. 8, pp. 1245-1253, 2010.

[12] S. G. Dozier, K. Schroeder, J. Lee, J. A. Fulkerson, and M. Y. Kubik, "The association between parents and children meeting physical activity guidelines," Journal of Pediatric Nursing, vol. 52, pp. 70-75, 2020.

[13] M. Pinquart, "Associations of general parenting and parentchild relationship with pediatric obesity: a meta-analysis," Journal of Pediatric Psychology, vol. 39, no. 4, pp. 381-393, 2014.

[14] E. F. Sleddens, S. M. Gerards, C. Thijs, N. K. De Vries, and S. P. Kremers, "General parenting, childhood overweight and obesity-inducing behaviors: a review," International Journal of Pediatric Obesity, vol. 6, no. 2-2, pp. e12-e27, 2011.

[15] M. J. Cox and B. Paley, "Understanding families as systems," Current Directions in Psychological Science, vol. 12, no. 5, pp. 193-196, 2003.

[16] T. N. Q. F. Gomes, F. K. dos Santos, R. M. Garganta, D. A. Kenny, P. T. Katzmarzyk, and J. A. R. Maia, "Multi-level modelling of physical activity in nuclear families," Annals of Human Biology, vol. 41, no. 2, pp. 138-144, 2014.

[17] Y. Wang, M. A. Beydoun, J. Li, Y. Liu, and L. A. Moreno, "Do children and their parents eat a similar diet? Resemblance in child and parental dietary intake: systematic review and meta-analysis," Journal of Epidemiology \& Community Health, vol. 65, no. 2, pp. 177-189, 2011.

[18] E. Roach, G. B. Viechnicki, L. B. Retzloff, P. Davis-Kean, J. C. Lumeng, and A. L. Miller, "Family food talk, child eating behavior, and maternal feeding practices," Appetite, vol. 117, pp. 40-50, 2017.

[19] S. Verjans-Janssen, D. Van Kann, S. Kremers, S. Vos, M. Jansen, and S. Gerards, "A cross-sectional study on the relationship between the family nutrition climate and children's nutrition behavior," Nutrients, vol. 11, no. 10, p. 2344, 2019.

[20] C. Niermann, F. Krapf, B. Renner, M. Reiner, and A. Woll, "Family health climate scale (FHC-scale): development and validation," International Journal of Behavioral Nutrition and Physical Activity, vol. 11, no. 1, p. 30, 2014. 
[21] J. Z. Carr, A. M. Schmidt, J. K. Ford, and R. P. DeShon, "Climate perceptions matter: a meta-analytic path analysis relating molar climate, cognitive and affective states, and individual level work outcomes," Journal of Applied Psychology, vol. 88, no. 4, pp. 605-619, 2003.

[22] V. Morrison and P. Bennett, An Introduction to Health Psychology, Pearson Education, 2009.

[23] S. Schoeppe, C. Vandelanotte, E. Bere et al., "The influence of parental modelling on children's physical activity and screen time: does it differ by gender?," The European Journal of Public Health, vol. 27, no. 1, article ckw182, 2016.

[24] S. Onayli and O. Erdur-Baker, "Mother-daughter relationship and daughter's self esteem," Procedia-Social and Behavioral Sciences., vol. 84, pp. 327-331, 2013.

[25] V. A. La Sorsa and I. G. Fodor, "Adolescent daughter/midlife mother dyad: a new look at separation and self-definition," Psychology of Women Quarterly, vol. 14, no. 4, pp. 593-606, 1990.

[26] A. T. Barnes, M. D. Young, E. M. Murtagh, C. E. Collins, R. C. Plotnikoff, and P. J. Morgan, "Effectiveness of mother and daughter interventions targeting physical activity, fitness, nutrition and adiposity: a systematic review," Preventive Medicine, vol. 111, pp. 55-66, 2018.

[27] H. Y. Chen and J. R. Boore, "Translation and back-translation in qualitative nursing research: methodological review," Journal of Clinical Nursing, vol. 19, no. 1-2, pp. 234-239, 2010.

[28] R. M. Kaplan and D. P. Saccuzzo, Psychological Testing: Principles, Applications, and Issues, Nelson Education, 2017.

[29] S. J. McKelvie, "Effects of format of the vividness of visual imagery questionnaire on content validity, split-half reliability, and the role of memory in test-retest reliability," British Journal of Psychology, vol. 77, no. 2, pp. 229-236, 1986.

[30] K. Schermelleh-Engel, H. Moosbrugger, and H. Müller, "Evaluating the fit of structural equation models: tests of significance and descriptive goodness-of-fit measures," Methods of Psychological Research Online, vol. 8, no. 2, pp. 23-74, 2003.

[31] M. Golan and S. Crow, "Parents are key players in the prevention and treatment of weight-related problems," Nutrition Reviews, vol. 62, no. 1, pp. 39-50, 2004.

[32] A. Hebestreit, K. M. Keimer, H. Hassel et al., "What do children understand? Communicating health behavior in a European multicenter study," Journal of Public Health, vol. 18, no. 4, pp. 391-401, 2010.

[33] K. Mikhailovich and P. Morrison, "Discussing childhood overweight and obesity with parents: a health communication dilemma," Journal of Child Health Care, vol. 11, no. 4, pp. 311-322, 2007.

[34] M. Rahimi and A. A. H. Karimi, "The study of the formation of consumer attitudes and intentions towards internal and external characteristics of fast food restaurants," International Research Journal of Applied and Basic Sciences, vol. 10, no. 3, 2016.

[35] R. N. de Sousa Silva and J. M. N. da Silva, "Prevalence of musculoskeletal pain in primary care dentists," Revista Dor, vol. 18, no. 3, pp. 225-231, 2017. 